\title{
BMJ A cross-sectional survey of healthcare open professionals to determine what they believe constitutes 'specialist' care for teenage and young adult patients with cancer
}

\author{
Rebecca J Birch, ${ }^{1}$ Eva J A Morris, ${ }^{2}$ Robert M West, ${ }^{3}$ Dan P Stark, ${ }^{4}$ Ian Lewis, ${ }^{5}$ \\ Sue Morgan, ${ }^{6}$ Richard G Feltbower ${ }^{1}$
}

To cite: Birch RJ,

Morris EJA, West RM, et al. A cross-sectional survey of healthcare professionals to determine what they believe constitutes 'specialist' care for teenage and young adult patients with cancer. BMJ Open 2013;3:e002346. doi:10.1136/bmjopen-2012002346

- Prepublication history for this paper are available online. To view these files please visit the journal online (http://dx.doi.org/10.1136/ bmjopen-2012-002346).

Received 14 November 2012 Revised 4 March 2013 Accepted 11 March 2013

This final article is available for use under the terms of the Creative Commons Attribution Non-Commercial 2.0 Licence; see http://bmjopen.bmj.com

For numbered affiliations see end of article.

Correspondence to

Rebecca Birch,

r.j.birch@leeds.ac.uk

\section{ABSTRACT}

Objectives: To examine the attitudes of UK healthcare professionals towards what they believe constitutes specialist care for teenage and young adult (TYA) patients with cancer, to determine which factors they considered to be the most important components of specialist TYA care, and whether opinion varied between clinical specialties and reflected the drivers for care improvements within National Health Service (NHS) policy.

Design and methods: The study utilised a crosssectional survey, using Likert scales, to assess attitudes towards specialist care. Responses were grouped using model-based clustering methods implemented in LatentGold 4.5.

Setting: Participants from 98 NHS trusts in the UK were invited to participate in the study.

Participants: 691 healthcare professionals involved in the management of TYA patients were approached; of these, 338 responded.

Results: 338 healthcare professionals responded (51.9\% of those invited). Responses were grouped into three clusters according to the pattern of responses to the questions. One cluster rated age-appropriate care above all else, the second rated both age and site-appropriate care highly while the third assigned more importance to site-specific care. Overall, the psychosocial and supportive aspects of care were rated highest while statements relating to factors known to be important (access to clinical trials, treatment at a high volume centre and specialist diagnostics) were not rated as highly as expected.

Conclusions: Attitudes varied widely between professionals treating TYA patients with cancer as to what constitutes key aspects of specialist care. Further work is needed to quantify the extent to which this influences practice.

\section{INTRODUCTION}

The incidence of cancer in teenagers and young adults (TYA) is rare compared with that in older adults. ${ }^{1}$ In recent years, only

\section{ARTICLE SUMMARY}

Article focus

- This study aimed to examine the difference in attitudes towards specialist care for teenage and young adult (TYA) patients with cancer among those involved in their care in an attempt to quantify the variation.

Key messages

- A wide range of attitudes towards specialist care is seen in those involved in the care of TYA patients with cancer.

- Three distinct groups of opinion exist, with each favouring a different aspect of care: age specific, cancer site specific or a combination of both.

Strengths and limitations of this study

- This is the first study of its kind to examine attitudes towards specialist care for TYA patients with cancer, and responses were received from a wide range of professionals with varying degrees of contact with TYA patients.

- Random sampling may have introduced bias, which is unavoidable using this methodology; however, results suggest that this was not a significant problem in this study.

- Further work would allow for responses from a wider study population and more in-depth examination of areas of disagreement.

around 2000 cases have been diagnosed annually in patients aged between 15 and $24 ;^{12}$ thus, its optimal management poses a major challenge to healthcare providers.

Challenges include not only the wide spectrum of cancers experienced by this age group but also the host and disease biology of these tumours, which can differ from that seen in both children and adults. ${ }^{3-6}$ Likewise, individuals in this age group also have very different psychosocial needs to 
either adults or children. ${ }^{7-9}$ The optimal setting to meet these biological and psychosocial needs is, therefore, not ideally managed by adult or children's cancer teams, but by a TYA-specialist team drawing expertise from both professional groups. The widely varying spectrum of cancers affecting this age group and their unusual position in terms of age-focused services has led many to argue in favour of specialist care ${ }^{10-12}$ However, owing to the different age-specific and cancer-specific care needs involved, there is, as yet, no consensus on what constitutes such 'specialist' care..$^{12-14}$

Access to tumour-specialist multidisciplinary teams (MDTs), age-specialist MDTs and specialist diagnostic services, clinical trials and specialist supportive services have all been cited as crucial to optimal outcomes in tumour site-specific guidelines (National Institute for Health and Clinical Excellence cancer service guidelines ${ }^{11}$ ). Other guidelines place more emphasis on the importance of age-specific services and the availability of psychosocial and late effects supportive care. ${ }^{15}$ Principal treatment centres (PTC) have been advocated where patients have access to specialist environments of care, as were appropriately trained professionals from both site-specific and age-specific teams working together closely. A larger degree of specialisation than other cancer units has been supported. Three different types of PTC exist with three different foci: TYA-specific (teenage cancer trust (TCT) unit), ${ }^{16}$ paediatric (Children's Cancer and Leukaemia Group (CCLG) unit) ${ }^{17}$ and cancer site-specific units. ${ }^{18}$ In some cases, a single centre may include all three types of specialist units.

There is known variation in where, how and by whom TYA patients with cancer are treated. ${ }^{19}{ }^{20}$ What is not fully understood is whether this is due to the availability of services (both geographically and age wise), patient's choice or physician's decision. Understanding the attitudes of those who treat this age range is vital to gaining a clearer insight into the key components of care of this age group, and therefore determining to what extent varying attitudes may be influencing the variation in treatment.

Policy states that treatment at a PTC is a key part of the cancer treatment pathway, as is access to clinical trials, MDT follow-up, age and cancer site appropriate care. ${ }^{11}$ The latter has not been examined in detail, and therefore this study aimed to examine the variation in attitudes towards specialist care for TYA patients among those involved in the treatment of this group, and to determine whether opinion mirrored policy. It also aimed to quantify any variation noted and to establish whether this was associated with specific characteristics of the respondents such as job title, type of centre and caseload.

\section{PARTICIPANTS AND METHODS}

Sample selection

A list of healthcare professionals from National Health Service (NHS) trusts across the UK (England, Scotland,
Wales and Northern Ireland) involved in the treatment of TYA patients were identified using NHS trust websites. Individuals, including doctors, nurses and other health professionals, such as radiographers and physiotherapists, with a specialty which involved the care of patients with cancer and whose contact details were available on the NHS trust website, were included. Email addresses were freely available for 98 trusts in the UK at the time of this study. Each individual was contacted by email during June 2009 and asked to complete the questionnaire and to forward it to others to whom it might have been of interest. Non-responders received two follow-up emails between December 2009 and February 2010.

\section{Survey development and study protocol}

The survey consisted of a list of statements (table 1) about factors that had been identified in the medical literature as being potentially important features of specialist TYA cancer care. ${ }^{10} 12 \quad 1921-25$ The statements encompassed both age-appropriate and site-specific features of care alongside more general aspects of cancer services. Respondents were asked to rate these 27 statements using a Likert scale (1-low importance to 5high importance). Questions regarding the age range that respondents deemed appropriate for TYA patients, respondent's specialty and affiliation with a TCT unit were also included.

\section{Statistical analysis}

Descriptive statistics were used to describe demographics of respondents. Mann-Whitney tests were used to examine the difference between demographic information and the responses on the 5-point Likert scale.

Missing information was recorded as such in the analysis, as the proportion of respondents who left each question blank was considered an interesting outcome in its own right.

Model-based latent cluster analysis was used to establish underlying characteristics and relationships that could be used to group data into natural/latent classes. The Bayesian information criterion score was used to determine the number of latent classes which provided the best fit to the respondents' data. The analysis was performed using Stata 11 and Latent Gold 4.5. ${ }^{27}$

\section{RESULTS}

Six hundred and ninety-one healthcare professionals from 98 NHS trusts were asked to complete the questionnaire and $338(51.9 \%)$ responded. The characteristics of the respondents are detailed in table 2. In all, 253 $(74.9 \%)$ were from England, 21 (6.2\%) from Northern Ireland, $30(8.9 \%)$ from Scotland and $34(10.1 \%)$ from Wales. One hundred and ninety (56.2\%) reported that they were affiliated with a teenage cancer unit and 208 $(61.5 \%)$ were linked to a CCLG unit. The majority of respondents belonged to a medical rather than a surgical specialism ( $78.4 \%$ vs $21.6 \%$, respectively). Over half 
Table 1 Responses

\begin{tabular}{|c|c|c|c|c|c|c|c|c|c|c|}
\hline \multirow[b]{2}{*}{ Rank } & \multirow[b]{2}{*}{$\mathbf{Q}$} & \multicolumn{2}{|c|}{$\begin{array}{l}4 \text { or } \\
\text { higher }\end{array}$} & \multicolumn{2}{|l|}{3} & \multicolumn{2}{|c|}{$\begin{array}{l}2 \text { or } \\
\text { lower }\end{array}$} & \multicolumn{2}{|c|}{ Missing } & \multirow[b]{2}{*}{ Question } \\
\hline & & $\bar{n}$ & $\%$ & $\bar{n}$ & $\%$ & $\bar{n}$ & $\%$ & $\bar{n}$ & $\%$ & \\
\hline 1 & 16 & 314 & 92.9 & 10 & 3.0 & 8 & 2.4 & 6 & 1.8 & $\begin{array}{l}\text { Psychological and psychosocial support from those } \\
\text { specialising in the care of teenagers and young adults. }\end{array}$ \\
\hline 2 & 14 & 314 & 92.9 & 11 & 3.3 & 8 & 2.4 & 5 & 1.5 & $\begin{array}{l}\text { Contact with a nurse specialising in the care of teenagers and } \\
\text { young adults. }\end{array}$ \\
\hline 3 & 13 & 303 & 89.6 & 18 & 5.3 & 13 & 3.8 & 4 & 1.2 & Treatment in an age-appropriate environment. \\
\hline 4 & 1 & 289 & 85.5 & 32 & 9.5 & 13 & 3.8 & 4 & 1.2 & Treatment by a site-specific surgical or medical team. \\
\hline 5 & 12 & 286 & 84.6 & 34 & 10.1 & 13 & 3.8 & 5 & 1.5 & Access to age-appropriate clinical trials. \\
\hline 6 & 21 & 285 & 84.3 & 32 & 9.5 & 18 & 5.3 & 3 & 0.9 & $\begin{array}{l}\text { Contact with peers who have undergone or are undergoing } \\
\text { similar treatments or who have been diagnosed with the same } \\
\text { illness. }\end{array}$ \\
\hline 7 & 6 & 285 & 84.3 & 38 & 11.2 & 10 & 3.0 & 5 & 1.5 & Regular follow-up by a site-specific MDT. \\
\hline 8 & 5 & 285 & 84.3 & 40 & 11.8 & 6 & 1.8 & 7 & 2.1 & $\begin{array}{l}\text { Contact with a site-specific clinical nurse specialist or } \\
\text { Macmillan nurse. }\end{array}$ \\
\hline 9 & 3 & 284 & 84.0 & 39 & 11.5 & 12 & 3.6 & 3 & 0.9 & Access to site-specific clinical trials. \\
\hline 10 & 2 & 282 & 83.4 & 39 & 11.5 & 13 & 3.8 & 4 & 1.2 & $\begin{array}{l}\text { Diagnostics and staging by site-specialist clinical teams } \\
\text { (radiology, pathology, etc) }\end{array}$ \\
\hline 11 & 10 & 256 & 75.7 & 44 & 13.0 & 34 & 10.1 & 4 & 1.2 & $\begin{array}{l}\text { Treatment by a medical or surgical team who specialise in the } \\
\text { treatment and care of teenagers and young adults. }\end{array}$ \\
\hline 12 & 15 & 236 & 69.8 & 57 & 16.9 & 39 & 11.5 & 6 & 1.8 & Regular follow-up by an age-specific MDT. \\
\hline 13 & 19 & 230 & 68.0 & 74 & 21.9 & 27 & 8.0 & 7 & 2.1 & Treatment at a high volume cancer centre. \\
\hline 14 & 11 & 195 & 57.7 & 86 & 25.4 & 52 & 15.4 & 5 & 1.5 & $\begin{array}{l}\text { Diagnostics and staging by clinical teams specialising in the } \\
\text { care of teenagers and young adults (radiology, pathology, etc) }\end{array}$ \\
\hline 15 & 7 & 194 & 57.4 & 10 & 3.0 & 6 & 1.8 & 128 & 37.9 & $\begin{array}{l}\text { Psychological and psychosocial support from those } \\
\text { specialising in the care of persons with cancer. }\end{array}$ \\
\hline 16 & 26 & 192 & 56.8 & 10 & 3.0 & 3 & 0.9 & 133 & 39.3 & $\begin{array}{l}\text { Access to fertility specialists and advice on reproductive } \\
\text { issues. }\end{array}$ \\
\hline 17 & 17 & 188 & 55.6 & 12 & 3.6 & 5 & 1.5 & 133 & 39.3 & Access to age-appropriate palliative care if needed. \\
\hline 18 & 24 & 186 & 55.0 & 16 & 4.7 & 4 & 1.2 & 132 & 39.1 & Support for family friends and partners of the patient. \\
\hline 19 & 18 & 184 & 54.4 & 15 & 4.4 & 7 & 2.1 & 132 & 39.1 & $\begin{array}{l}\text { Access to age-appropriate end of treatment care and support } \\
\text { and information on late effects of treatment. }\end{array}$ \\
\hline 20 & 23 & 183 & 54.1 & 18 & 5.3 & 5 & 1.5 & 132 & 39.1 & $\begin{array}{l}\text { Educational and employment support during and after } \\
\text { treatment. }\end{array}$ \\
\hline 21 & 27 & 179 & 53.0 & 17 & 5.0 & 9 & 2.7 & 133 & 39.3 & $\begin{array}{l}\text { Ability to stay in contact with peers when in hospital, } \\
\text { Facebook, email text messages, etc }\end{array}$ \\
\hline 22 & 9 & 168 & 49.7 & 28 & 8.3 & 13 & 3.8 & 129 & 38.2 & $\begin{array}{l}\text { Access to site-specific end of treatment care and support and } \\
\text { information on late effects of treatment. }\end{array}$ \\
\hline 23 & 25 & 167 & 49.4 & 30 & 8.9 & 10 & 3.0 & 131 & 38.8 & Treatment by the same team throughout. \\
\hline 24 & 8 & 160 & 47.3 & 30 & 8.9 & 17 & 5.0 & 131 & 38.8 & Access to site-specific palliative care if needed. \\
\hline 25 & 22 & 141 & 41.7 & 43 & 12.7 & 22 & 6.5 & 132 & 39.1 & $\begin{array}{l}\text { Outpatient appointments held in an age-appropriate } \\
\text { environment. }\end{array}$ \\
\hline 26 & 20 & 129 & 38.2 & 116 & 34.3 & 86 & 25.4 & 7 & 2.1 & $\begin{array}{l}\text { Treatment at a hospital in close proximity to a patient's home } \\
\text { address. }\end{array}$ \\
\hline 27 & 4 & 114 & 33.7 & 90 & 26.6 & 128 & 37.9 & 6 & 1.8 & Inpatient treatment on a site-specific ward (eg, breast). \\
\hline
\end{tabular}

of all those who responded $(55.7 \%)$ reported that less than $10 \%$ of their annual workload comprised TYA patients and only 35 respondents $(16.8 \%)$ reported seeing more than 20 TYA oncology patients annually. In total, 129 respondents $(38.2 \%)$ failed to report the number of TYA patients treated annually; however, only $2(0.6 \%)$ failed to report the proportion of their total caseload which consisted of TYA patients. The most frequently suggested lower age range for a TYA service was 13 (52.7\%, range $11-19$ years of age) and the most commonly (modal) recommended upper age limit was $25(25.7 \%$, range $16-40$ years of age).

Many respondents also recorded that the patient range should not be restricted by age but by the diagnostic group and emotional maturity of the patient. The latent class model identified three clusters of respondents with specific attitudes concerning specialist care (figure 1).

Cluster 3 rated the treatment by a site-specific team higher than an age-specialist team, but did not rate any 
Table 2 Characteristics of respondents

\begin{tabular}{|c|c|c|c|c|c|c|c|}
\hline & \multicolumn{2}{|c|}{ Cluster 1} & \multicolumn{2}{|c|}{ Cluster 2} & \multicolumn{2}{|c|}{ Cluster 3} & \multirow[b]{2}{*}{ Tota } \\
\hline & $\overline{\mathbf{n}}$ & $\%$ & $\overline{\mathbf{n}}$ & $\%$ & $\overline{\mathbf{n}}$ & $\%$ & \\
\hline \multicolumn{8}{|l|}{ Country } \\
\hline England & 100 & 34.0 & 107 & 36.4 & 87 & 29.6 & 294 \\
\hline Scotland & 6 & 40.0 & 5 & 33.3 & 4 & 26.7 & 15 \\
\hline Wales & 5 & 27.8 & 9 & 50.0 & 4 & 22.2 & 18 \\
\hline Northern Ireland & 3 & 27.3 & 3 & 27.3 & 5 & 45.5 & 11 \\
\hline \multicolumn{8}{|l|}{ Self-reported job title } \\
\hline Doctor & 99 & 42.3 & 69 & 29.5 & 66 & 28.2 & 234 \\
\hline Nurse & 9 & 14.1 & 36 & 56.3 & 19 & 29.7 & 64 \\
\hline Radiographer & 1 & 10.0 & 1 & 10.0 & 8 & 80.0 & 10 \\
\hline Management & 1 & 14.3 & 3 & 42.9 & 3 & 42.9 & 7 \\
\hline Social worker & 0 & 0.0 & 3 & 60.0 & 2 & 40.0 & 5 \\
\hline Other & 4 & 23.5 & 11 & 64.7 & 2 & 11.8 & 17 \\
\hline Unknown & 0 & 0.0 & 1 & 100.0 & 0 & 0.0 & 1 \\
\hline \multicolumn{8}{|l|}{ Specialism } \\
\hline Medical & 92 & 33.9 & 103 & 38.0 & 76 & 28.0 & 271 \\
\hline Surgical & 22 & 32.8 & 21 & 31.3 & 24 & 35.8 & 67 \\
\hline \multicolumn{8}{|l|}{ Area of expertise } \\
\hline Oncology & 38 & 26.8 & 57 & 40.1 & 47 & 33.1 & 142 \\
\hline Haematology & 27 & 60.0 & 13 & 28.9 & 5 & 11.1 & 45 \\
\hline Paediatrics & 10 & 55.6 & 1 & 5.6 & 7 & 38.9 & 18 \\
\hline Gynaecology & 2 & 11.1 & 10 & 55.6 & 6 & 33.3 & 18 \\
\hline ENT & 8 & 50.0 & 6 & 37.5 & 2 & 12.5 & 16 \\
\hline Palliative medicine & 4 & 26.7 & 10 & 66.7 & 1 & 6.7 & 15 \\
\hline General surgery & 3 & 21.4 & 4 & 28.6 & 7 & 50.0 & 14 \\
\hline Radiology & 0 & 0.0 & 3 & 30.0 & 7 & 70.0 & 10 \\
\hline Other surgical specialty & 18 & 35.0 & 2 & 15.0 & 15 & 45.0 & 35 \\
\hline Other non-surgical specialty & 6 & 42.9 & 5 & 35.7 & 4 & 21.4 & 15 \\
\hline Other & 6 & 42.9 & 14 & 35.7 & 6 & 21.4 & 26 \\
\hline \multicolumn{8}{|l|}{ Type of specialist interest } \\
\hline Age & 9 & 18.4 & 15 & 30.6 & 25 & 51.0 & 49 \\
\hline Site & 79 & 39.3 & 72 & 35.8 & 50 & 24.9 & 201 \\
\hline Both & 26 & 29.9 & 36 & 41.4 & 25 & 28.7 & 87 \\
\hline Unknown & 0 & 0.0 & 1 & 100.0 & 0 & 0.0 & 1 \\
\hline \multicolumn{8}{|l|}{ Teenage cancer unit } \\
\hline Yes & 58 & 30.5 & 83 & 43.7 & 49 & 25.8 & 190 \\
\hline No & 56 & 37.8 & 41 & 27.7 & 51 & 34.5 & 148 \\
\hline \multicolumn{8}{|l|}{ CCLG unit } \\
\hline Yes & 70 & 33.7 & 70 & 33.7 & 68 & 32.7 & 208 \\
\hline No & 44 & 33.8 & 54 & 41.5 & 32 & 24.6 & 130 \\
\hline \multicolumn{8}{|c|}{ Number of TYA patients seen annually } \\
\hline $0-5$ & 43 & 44.3 & 28 & 28.9 & 26 & 26.8 & 97 \\
\hline $6-10$ & 25 & 52.1 & 10 & 20.8 & 13 & 27.1 & 48 \\
\hline $11-15$ & 3 & 16.7 & 8 & 44.4 & 7 & 38.9 & 18 \\
\hline $16-20$ & 3 & 27.3 & 5 & 45.5 & 3 & 27.3 & 11 \\
\hline $21+$ & 3 & 8.6 & 17 & 48.6 & 15 & 42.9 & 35 \\
\hline Unknown & 37 & 28.7 & 56 & 43.4 & 36 & 27.9 & 129 \\
\hline \multicolumn{8}{|c|}{ Proportion of overall caseload consisting of TYA } \\
\hline Less than $10 \%$ & 87 & 46.3 & 47 & 25.0 & 54 & 28.7 & 188 \\
\hline $10-20 \%$ & 14 & 26.9 & 23 & 44.2 & 15 & 28.8 & 52 \\
\hline $20-30 \%$ & 6 & 19.4 & 11 & 35.5 & 14 & 45.2 & 31 \\
\hline $30-40 \%$ & 4 & 26.7 & 9 & 60.0 & 2 & 13.3 & 15 \\
\hline Greater than $40 \%$ & 3 & 6.0 & 32 & 64.0 & 15 & 30.0 & 50 \\
\hline Unknown & 0 & 0.0 & 2 & 100.0 & 0 & 0.0 & 2 \\
\hline \multicolumn{8}{|l|}{ Total } \\
\hline 114 & 33.7 & 124 & 36.7 & 100 & 29.6 & 338 & \\
\hline
\end{tabular}

CCLG, Children's Cancer and Leukaemia Group; TYA, teenage and young adult. 
Figure 1 Cluster analysis of responses to the survey.

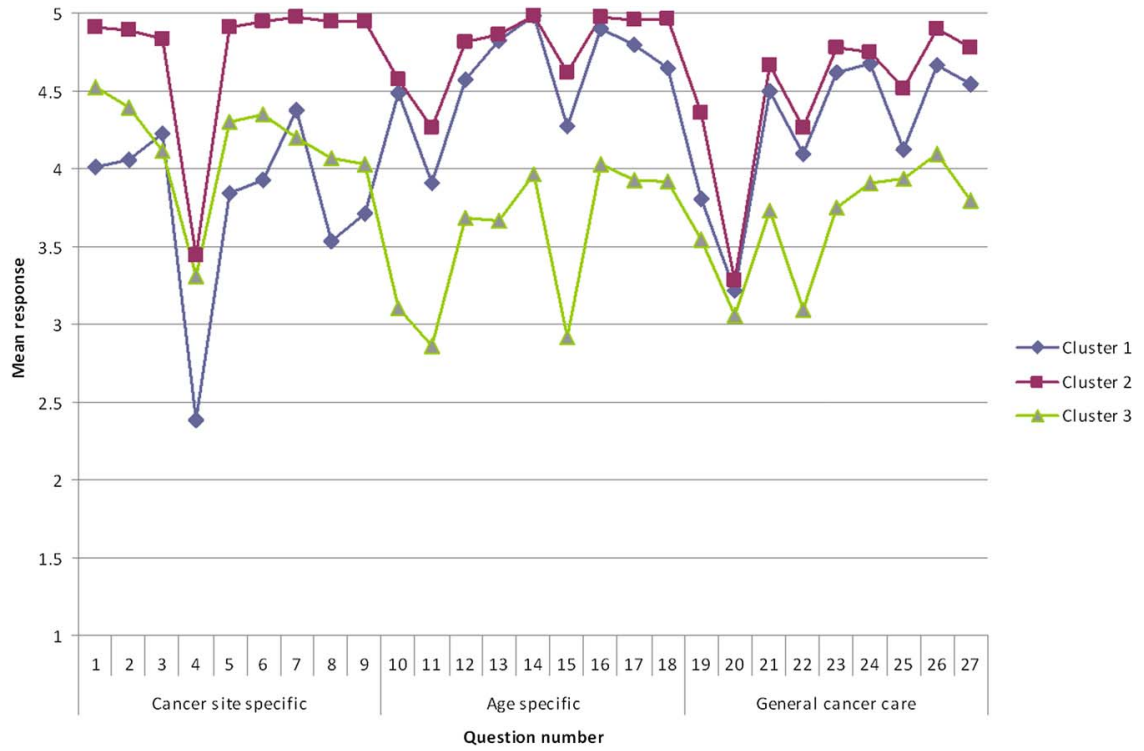

of the statements as highly as clusters 1 and 2, indicating that individuals in cluster 3 answered more questions as being of neither high nor low importance.

Cluster 1 rated age-appropriate treatment very highly in all areas while cluster 2 rated most points highly and did not favour either age-specialist or site-specialist care. Overall, it appeared that clusters should be grouped as follows:

\section{Cluster 1-Age-specific preference}

Cluster 2-Combined age-specific and site-specific preference

Cluster 3-Cancer site-specific preference

The variation in responses between the three clusters was statistically significant for all questions $(p \leq 0.01)$, with the exception of question $20(p=0.61)$.

On further examination of the self-reported interests of the respondents (table 2), the distribution of those affiliated with a TCT or a CCLG unit was found to be even across the three clusters. The majority of individuals in cluster 3, which favoured site-specialist treatment, had a site-specific interest (eg, colorectal or breast surgery), and contained a greater proportion of those with a surgical specialty than any other cluster. Persons within cluster 2 treated the highest number of TYA cases annually, while cluster 1 treated the lowest, with 68 respondents reporting seeing fewer than 11 cases annually.

When the questions were ranked in order of importance, the three questions ranked mostly highly were (table 1): (1) psychological and psychosocial support from those specialising in the care of TYA (314 respondents $(92.9 \%)$ marked as a 4 or higher); (2) contact with a nurse specialising in the care of TYA (314 respondents $(92.9 \%)$ marked as a 4 or higher); and (3) treatment in an age-appropriate environment (303 respondents $(89.6 \%)$ marked as a 4 or higher). The three statements ranked the lowest were: (1) inpatient treatment on a sitespecific ward (eg, breast) (128 respondents $(37.9 \%)$ marked as a 2 or lower); (2) treatment at a hospital in close proximity to a patient's home address
(86 respondents $(25.4 \%)$ marked as a 2 or lower); and (3) diagnostics and staging by clinical teams specialising in the care of teenagers and young adults (radiology, pathology, etc) (52 respondents (15.4\% marked as a 2 or lower). The three statements which ranked the lowest also had the greatest number of indifferent responses (scored 3 on the Likert scale). Aspects of care often discussed as being key aspects of specialist care for TYA patients by patients themselves ${ }^{8}$ ranked relatively low on the scale. Access to clinical trials, particularly site-specific, ranked around the middle of the table of ordered responses (ranked ninth most important). Treatment at a high volume cancer centre was also ranked of relatively low importance with only 230 respondents $(68.0 \%)$ scoring this 4 or higher and $74(21.9 \%)$ recording it as neither of high nor low importance.

Statements ranked 15 th to 25 th overall were unanswered in over $35 \%$ of cases. These questions related mainly to psychosocial support, palliative care and long-term follow-up. This was vastly different to the number of missing answers for other questions (range 3-7 missing answers). The focus of these questions may have led a greater proportion of respondents to leave them unanswered; previous studies have shown a patchy and irregular referral to supportive services, suggesting a greater degree of indifference than shown in the other areas addressed in the study. 2728

\section{DISCUSSION}

This study demonstrates widely varying opinions as to what is important in the care of TYA patients with cancer. Attitudes were divided into three categories: those who advocated age-appropriate care, those who preferred tumour-site-specialist care and those who promoted a combination of both age-specialist and sitespecialist care. The characteristics of individuals in these three clusters were different, with specialism, caseload 
and involvement with either a TYA or a CCLG unit varying between groups. Aspects of care which are frequently the focus of policy, such as access to a high volume cancer centre and access to clinical trials, were assigned lower importance than expected, as were all aspects related to end of life care.

Current policy states that all patients in the TYA age range should at least be offered the opportunity to be treated at a PTC and to receive specialist care. ${ }^{11}$ This study reflects the varying attitudes towards specialist care for this age group and illustrates the difficulties in fully implementing policy in relation to the differing degrees of importance associated to it. Where the rhetoric is not believed by all those involved in the diagnostic, treatment and support pathway for this patient group, and as long as flexibility remains, specialist TYA cancer care, as it is currently defined, will not be implemented consistently.

As a relatively young area of cancer treatment with a multitude of diagnoses and treatment options, the pathways and protocols for TYA cancer care are known to vary. Not all TYA patients are treated at TYA specialist units; in some cases, this may be due to patient choice, while in others it could be due to a lack of appropriate referral to the units. This variation alongside the disagreement as to what constitutes the key aspects of care for TYA with cancer may demonstrate the need for multidisciplinary involvement in order to ensure that patients receive the best of all elements of care. All the respondents to this survey were actively involved in the treatment of TYA patients but have extremely divergent views as to what constitutes 'specialist' care; this may go some way to explain why there is variation in how and where many TYA patients are treated. A preference towards one type of care, age or site over another may lead to an increased likelihood of favouring that care setting and a decreased chance of utilisation of other available services.

\section{Wider implications}

This study did not ask respondents whether their attitudes to specialist care would influence their practice but instead focused on the importance assigned to individual aspects of care in the wider picture. In an area such as TYA cancer care, where policy implementation is known to vary by geography and patient demographics, there is a degree of flexibility in terms of patient pathways. The attitude of professionals involved at each stage of the patient's journey is likely to at least partly influence the choices made. Unfortunately, in this case it was not possible to assess the extent to which the influence of clinicians varies at different points in the diagnostic and treatment pathways. Understanding the range and strength of opinions is vital before attempting to determine to what extent it influences practice. Policy states that patients should be reviewed by both a TYA and a site-specific MDT, emphasising that these should not be considered mutually exclusive.

\section{Limitations}

This is the first study to examine attitudes towards specialist cancer care in this age group. The method of recruitment to the study (random sampling) may have introduced bias, with those treating a high volume of TYA patients, and those belonging to a medical specialty, being more likely to reply than others. It is not possible to address this issue in a random sample study of this nature; however, the self-reported caseload figures and distribution of medical staff across the clusters (table 2) suggest that this has not been a significant problem. A similar issue was also identified regarding the proportion of respondents who identified an affiliation with a CCLG unit, which may have been due to the relatively large number of centres in comparison to TCT centres at the time of the study. Respondents were asked to identify any association between themselves and a specialist unit, including occasional contact, so this does not necessarily mean that this will have resulted in bias in the results.

A large proportion of questions regarding psychosocial support were unanswered; the reasoning behind this is not understood and, owing to the nature of the survey (Likert scale), it was not possible to investigate this in more detail. Additional work could be performed to address this using a more detailed survey assessing these aspects of care.

This study was undertaken in 2009, 5 years after the release of the Improving Outcomes Guidelines, and therefore will be reflective of attitudes to specialist care after the service redesign. Attitudes are likely to have altered since the survey was undertaken; however, the greatest degree of change is likely to have taken place relatively quickly after the publication of the guidance. In order to quantify any further changes in opinion, the study could be performed again, using a similar cohort.

Further work is also now needed to assess to what extent the attitudes of those treating TYA patients with cancer influence their practice, including an analysis of the attitudes of those referring patients for treatment and an assessment of the degree of variation between NHS trusts and cancer networks. In order to assess the different influences which may be affecting the variation in attitudes, such as proximity to a specialist centre and duration of association with a PTC, greater detail regarding the location and affiliation of the respondents would be sought and analysed. Additional work to determine any association between attitude and patient decisionmaking and variation in attitudes and patient outcomes would also add more detail to the understanding of a complex area.

\footnotetext{
Author affiliations

${ }^{1}$ Paediatric Epidemiology Group, University of Leeds, Leeds, UK

${ }^{2}$ Cancer Epidemiology Group, St James's Institute of Oncology, Leeds, UK

${ }^{3}$ Leeds Institute of Health Sciences, University of Leeds, Leeds, UK

${ }^{4}$ Leeds Institute of Molecular Medicine, University of Leeds, Leeds, UK

${ }^{5}$ Alder Hey Children's Hospital, Liverpool, UK

${ }^{6}$ Leeds Teaching Hospitals NHS Trust, Leeds, UK
} 
Contributors RJB designed data collection tools, monitored data collection for the whole trial, wrote the statistical analysis plan, cleaned and analysed the data, and drafted and revised the paper. She is the guarantor. EJAM aided in the statistical analysis, drafted and revised the paper. RMW designed data collection tools, aided in statistical analysis and revised the draft paper. DPS aided in the design of the study, drafted and revised the paper. IL aided in the design of the study, drafted and revised the paper. SM aided in the design of the study, drafted and revised the paper. RGF drafted and revised the paper. All authors read and approved the final manuscript.

Funding Cancer Research UK. PhD grant (473630).

Competing interestsNone.

Ethics approval This survey was undertaken as part of the PhD of Rebecca Birch, which is covered by ethics approval from the NRES Committee Yorkshire \& The Humber (08/H1302/87). Ethics was not sought individually for this study due to the nature of the survey.

Provenance and peer review Not commissioned; externally peer reviewed

Data sharing statement No additional data are available.

\section{REFERENCES}

1. Cancer Research UK. Cancer incidence by age. http://www. cancerresearchuk.org/cancer-info/cancerstats/incidence/age/ (accessed Feb 2013).

2. North West Cancer Intelligence Service. Average annual number of cases (2007-2009). http://www.nwcis.nhs.uk/tya/tables/incidence/ sha_19-24.aspx (accessed Feb 2013).

3. Alston RD, Rowan S, Eden TO, et al. Cancer incidence patterns by region and socioeconomic deprivation in teenagers and young adults in England. Br J Cancer 2007;96:1760-6.

4. Bleyer A, Budd T, Montello M. Adolescents and young adults with cancer. Cancer 2006;107(S7):1645-55.

5. Bleyer WA. Cancer in older adolescents and young adults: epidemiology, diagnosis, treatment, survival, and importance of clinical trials. Med Pediatr Oncol 2002;38:1-10.

6. Lewis IJ. Cancer in adolescence. Br Med Bull 1996;52:887-97.

7. Felder-Puig R, Formann AK, Mildner A, et al. Quality of life and psychosocial adjustment of young patients after treatment of bone cancer. Cancer 2000;83:69-75.

8. Roberts CS, Turney ME, Knowles AM. Psychosocial issues of adolescents with cancer. Soc Work Health Care 1998;27:3-18.

9. Smith $\mathrm{S}$, Davies $\mathrm{S}$, Wright $\mathrm{D}$, et al. The experiences of teenagers and young adults with cancer-results of 2004 conference survey. Eur J Oncol Nurs 2007;11:362-8.

10. Hollis R, Morgan S. The adolescent with cancer-at the edge of no-man's land. Lancet Oncol 2001;2:43-8.
11. National Institute for Health and Clinical Excellence. Improving outcomes in children and young people with cancer. London: National Institute for Health and Clinical Excellence, 2005.

12. Whelan J. Where should teenagers with cancer be treated? Eur J Cancer 2003;39:2573-8.

13. Newburger PE, Elfenbein DS, Boxer LA. Adolescents with cancer: access to clinical trials and age-appropriate care. Curr Opin Pediatr 2002;14:1-4.

14. Wilkinson J. Young people with cancer-how should their care be organized? Eur J Cancer Care (Engl) 2003;12:65-70.

15. Smith S, Case L, Waterhouse K, et al. A blueprint of care for teenagers and young adults with cancer. TCT and TYAC, 2012 Feb 1.

16. Teenage Cancer Trust. Teenage Cancer Trust-units. 2013. http:// www.teenagecancertrust.org/what-we-do/specialist-services/units/ (Accessed Feb 2013).

17. Children's Cancer and Leukaemia Group. Organisation of CCLG 2013. http://www.cclg.org.uk/about-us/organisation-of-cclg (accessed Feb 2013)

18. NHS Specialised Services. National Specialised Commissioning Group (NSCG). 2013. http://www.specialisedservices.nhs.uk/info/ nscg (accessed Feb 2013).

19. Pearce S. Policy and practice in teenage and young adult cancer care in England: Looking to the future. Eur $\mathrm{J}$ Oncol Nurs 2009;13:149-53.

20. Whelan J, Dolbear C, Mak V, et al. Where do teenagers and young adults receive treatment for cancer? J Public Health 2007;29:178-82.

21. Abrams AN, Hazen EP, Penson RT. Psychosocial issues in adolescents with cancer. Cancer Treat Rev 2007;33:622-30.

22. Fern L, Davies S, Eden T, et al. Rates of inclusion of teenagers and young adults in England into National Cancer Research Network clinical trials: report from the National Cancer Research Institute (NCRI) Teenage and Young Adult Clinical Studies Development Group. Br J Cancer 2008;99:1967-74.

23. Mitchell W, Clarke S, Sloper P. Care and support needs of children and young people with cancer and their parents. Psychooncology 2005;15:805-16.

24. Morgan S, Davies S, Palmer S, et al. Sex, drugs, and rock \& roll: caring for adolescents and young adults with cancer. $J$ Clin Oncol 2010;28:4825-30

25. Reynolds BC, Windebank KP, Leonard RCF, et al. A comparison of self-reported satisfaction between adolescents treated in a teenage unit with those treated in adult or paediatric units. Pediatr Blood Cancer 2004:44:259-63.

26. LatentGOLD 4.5 [computer program]. 2008.

27. Clerici CA, Massimino M, Casanova M, et al. Psychological referral and consultation for adolescents and young adults with cancer treated at pediatric oncology unit. Pediatr Blood Cancer 2008:51:105-9.

28. Kam LYK, Knott VE, Wilson C, et al. Using the theory of planned behavior to understand health professionals' attitudes and intentions to refer cancer patients for psychosocial support. Psychooncology 2012;21:316-23. 